\title{
Development of Control Strategies and Implementation to Electrical Water Heaters for Energy Conservation
}

\author{
Ahmet Feyzioglu 1 , A. Kerim Kar ${ }^{2}$ \\ ${ }^{1}$ Marmara University, Faculty of Technology, 34722 Marmara, Turkey \\ ${ }^{2}$ Marmara University, Faculty of Engineering, 34722 Marmara, Turkey \\ Emails:ahmet.feyzioglu@marmara.edu.trakar@marmara.edu.trahmet.feyzioglu@ marmara.edu.tr
}

Abstract: Optimum design for storage type Electric Water Heaters (EWHs) was analyzed for energy conservation and maximum hot water output. Single and dual tank EWHs were compared with each other. For each comparison, data were gathered for tank volumes and power ratings ranging 100-400 $l$ and $1-4 \mathrm{~kW}$ respectively. Different dual tank EWHs were designed with different control mechanisms to find which one had the optimum outcome. For these comparisons, dual tank EWHs in which the upper part of the tanks had $25 \%$ of the total volume and $75 \%$ of the total power rating were used. A five day usage period of an EWH in a typical household was simulated on SIMULINK. To minimize this energy loss, transient analysis on FLUENT was performed to see how long it took for the outlet water temperature. In these simulations, single and dual tank EWHs with different control mechanisms were compared with each other to find the design with minimum energy consumption and maximum hot water output. From these results the most efficient control system cost analysis was determined for minimum operating cost and minimum carbon footprint through optimized control strategies.

Keywords: Control, energy efficiency, optimization, steady-state heat transfer, water heaters.

\section{Introduction}

In many countries, a large number of households use electrical water heaters for domestic hot water consumption. Storage type electrical water heater is one of the most common ways of heating water by utilizing electricity for domestic use. A domestic electrical water heater is a simple system made of but not limited to an insulated tank, one or more heating elements, control and safety devices, and associated piping. Electrical water heaters are more flexible in design than other types of water heating appliances.

Compared to large central hot-water systems, the simplicity, reliability and low cost of storage-type electrical water heaters are their main advantages. In addition, 
water consumption is less for electrical water heaters since a shorter period of time is needed for the water to warm up to acceptable temperatures at the fixture.

The only disadvantage of storage-type domestic electrical water heaters is their excessive consumption of electrical energy. $\mathrm{Kar}$ and $\mathrm{Kar}$ [1] compared the performance of dual-tank electrical water heaters in series with a single-tank electrical water heater in terms of daily hot water output and energy saving per liter of maximum hot water produced. They concluded that a dual-tank electrical water heater of the same volume and power rating as a single-tank electrical water heater, where the second tank had $25 \%$ of the total volume and $75 \%$ of the total power rating, provided maximum hot water with the minimum electricity consumption. However, this idea required modifications in the classical design of electrical water heaters, which increased the cost and complexity of such cheap and simple units.

Storage tanks can: Reduce the number of times the heat pump compressor starts; adapt the capacity of heat generation to heat demand; which can offer the possibility to use low rate electricity [2].

A state estimation of a stratified tank study is made by K r e u z in ge r, B i t z e r and $\mathrm{Marquardt}$ [3]. Basically the research includes the design of two different state estimation approaches, namely a distributed parameter observer late lumping design and an Unscented Kalman Filter (UKF) early lumping design on the basis of a distributed and a lumped parameter system representation of a stratified storage tank for domestic hot water storage. The compared variables are practical applicability, convergence behaviour and number of function evaluations. Data show that the observer and the UKF converge equally fast and reconstruct the temperature profile in the storage tank comparably well. Moreover number of calculations the practical applicability and the cost of it outperforms the UKF.

The thermal performance of storage tanks depends on the rate of mixing between the incoming cold water and the stored hot water. In this study, a storage type domestic electrical water heater was investigated by using an average hourly hot water usage profile in order to find the design with the lowest energy consumption. In addition to that, hot water output capabilities were investigated. Using the dual tank model, tank was divided into two parts with varying volumes and electrical energy inputs. Some different control methods were applied and compared with each other. Lastly, optimum tank model was defined. Cost analyses for single and double tanks were given. For each simulation on SIMULINK, five-days duration was chosen to make sure that the results would apply to steady state condition. To minimize this energy loss, transient analysis on FLUENT was performed to see how long it took for the outlet water temperature. ANSI standards were considered throughout the study.

\section{Methods - tank modelling}

\subsection{Hourly hot water usage profile}

To obtain the maximum hot water output in dual tank Electrical Water Heaters (EWHs), the control mechanism of the two heaters must be chosen carefully. Previous studies on this topic found out that the optimum hot water flow results were 
obtained when the ratio of first tank's volume to the second tank's volume was chosen as 3:1 and the corresponding ratio of power ratings was chosen as 1:3 [1]. The simulations for this study were done by using these ratios.

The statistical studies show that hourly averages of hot water consumption vary a lot throughout the day. Fig. 1 shows the average hot water consumption of a typical family in the US for every hour of the day.

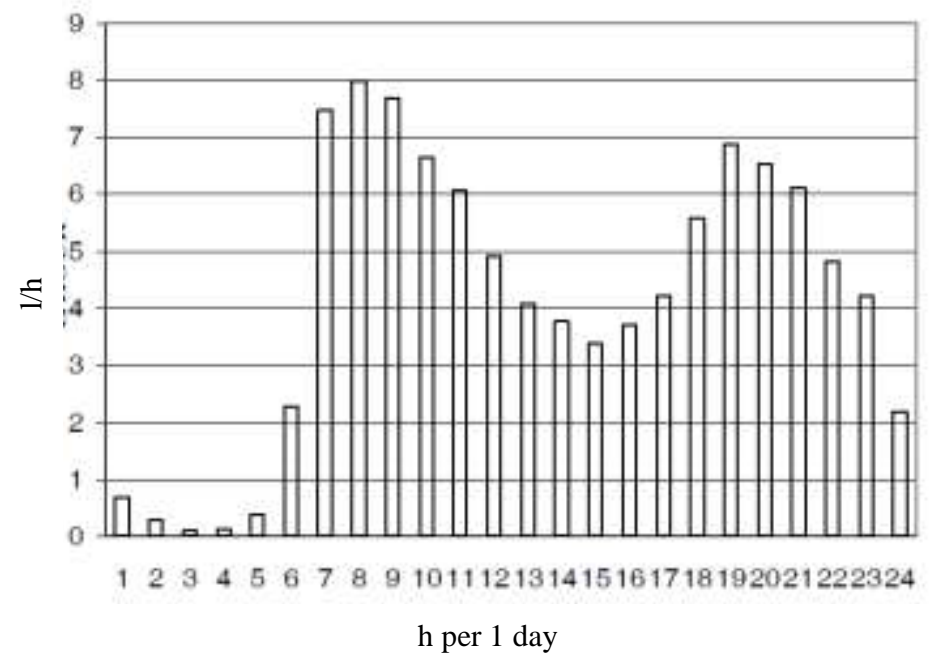

Fig. 1. Becker's hourly hot water use profile [4]

In our simulations, the hot water consumption $(1 / \mathrm{h})$ values from Fig. 1 were multiplied by a constant in order to see the maximum available hot water output without changing the hourly pattern. The pattern was not to change so that the usage of such a device in daily life could be simulated more precisely. However, some families could need more hot water through the day. For that reason, to obtain the maximum flow rate in Matlab/Simulink, this multiplier was increased until the temperature of the output water decreased below $60{ }^{\circ} \mathrm{C}$. Matlab Code was developed to optimize working intervals of the heaters. Assumed that control mechanism has a memory and as a result it knows the water flow pattern at any time. In this code, according to the flow rate value of the "next time" $t+1$, the heaters take action at time " $t$ ". By this mechanism, Users are able to determine the optimum control scheme of the heaters at maximum flow rate. Based on this principle; P, PI, PID and preview controls for different inlet and outlet designs are analyzed.

\subsection{Single tank modelling}

The single tank electric EWH used in this study was modelled as a homogeneous tank with one electric heating element as shown in Fig. 2. 


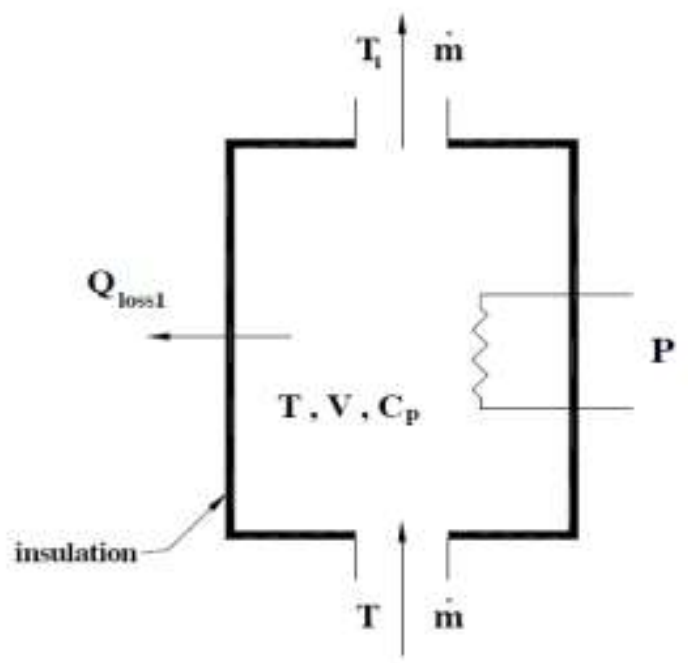

Fig. 2. Schematic diagram of a single tank EWH [1]

These EWHs were modelled as steel tanks with a wall thickness of $2 \mathrm{~mm}$, and $50 \mathrm{~mm}$ fiber glass insulation on the outside [5]. For each tank, the relation of the outside surface area to the volume was approximated as

(1)

$$
A=6 V^{2 / 3} \text {, }
$$

by taking the height to diameter ratio as 2 and expecting about $10 \%$ increase in the outside surface area due to insulation thickness.

Then, heat loss from the tank surface was calculated as [6]

(2)

$$
Q_{\text {loss }}=U A\left(T-T_{\mathrm{a}}\right) \text {, }
$$

where $U$ is the overall heat transfer coefficient, $A$ is the surface area of the tank, $T$ is the hot water temperature inside the tank in the appropriate section and $T_{\mathrm{a}}$ is the surrounding air temperature which was taken as $20{ }^{\circ} \mathrm{C}$. The incoming water temperature, $T_{\mathrm{i}}$, was taken to be $15^{\circ} \mathrm{C}$ for the calculations.

In this study, EWH problem involved mass and heat flow in and out of the system and, therefore, was modelled with a control volume, as shown in Fig. 2. A cold water stream with a mass flow rate $\dot{m}$ flowed continuously into the EWH, and a hot-water stream of the same mass flow rate flowed continuously out of it (hot water was assumed to be incompressible). The EWH, which was the control volume, was losing heat to the surrounding air at a rate of $\dot{Q}$, and the electric heating element was doing electrical work on the water (heating) at the rate of $\dot{W}$. The control volume was storing energy at a rate of $\frac{d E_{\mathrm{cv}}}{d t}$. By this line of reasoning, the first law of thermodynamics for this EWH becomes [4]

$$
\frac{d E_{\mathrm{cv}}}{d t}=\dot{Q}-\dot{W}+\sum \dot{m} h_{\mathrm{i}}-\sum \dot{m} h_{\mathrm{e}}
$$

where $h$ is the enthalpy of the flowing hot water (kinetic and potential energy changes were assumed to be negligible).

Equation (3) can also be written as [4] 


$$
\rho V C_{P} \frac{d T}{d t}=P+\dot{m} C_{P}\left(T_{\mathrm{i}}-T\right)-A U\left(T-T_{\mathrm{a}}\right),
$$

by making the substitutions [4]

$$
E_{\mathrm{cv}}=\rho V C_{P} T \text { (internal energy of control volume), }
$$

$$
\begin{gathered}
\dot{Q}=-A U\left(T-T_{\mathrm{a}}\right)(\text { Rate of heat loss to environment), } \\
\dot{W}=-P(\text { electrical power input to EWH }),
\end{gathered}
$$

where $T$ is the temperature of hot water in the tank, $V$ is the volume of the tank, $\rho$ is the density of water, $T_{\mathrm{i}}$ and $T_{\mathrm{a}}$ are incoming cold water and surrounding temperatures respectively, $C_{p}$ is the specific heat of the water at constant pressure and $t$ is time.

For the simulations single tank EWHs with tank sizes of 100, 200, 300 and 4001 were selected. Power ratings of 1,2, 3 and $4 \mathrm{~kW}$ were used for each tank during optimization. At the beginning of each optimization, the temperature of the hot water in the heater was assumed to be $60^{\circ} \mathrm{C}$, and according to ANSI Standards, it was kept between 60 and $65^{\circ} \mathrm{C}$ during the optimization. An on-off thermostatic controller was used to keep the temperatures in this range. Parametric optimization was performed on single-tank EWHs to obtain the maximum amount of daily hot water producible for each tank volume and power rating. This was accomplished by implementing the previously given equations and distributing the hourly hot water production according to the daily total hot water consumption pattern given in Fig. 1.

\subsection{Dual tank modelling}

The dual tank EWH considered in this study was made of two tanks connected in series, as shown in Fig. 3. Their total volume capacities and power ratings were the same as those of the corresponding single tank EWHs. Individual volumes and power ratings of the two tanks were added to get the total EWH volumes and power ratings $\left(V=V_{1}+V_{2}\right.$ and $\left.P=P_{1}+P_{2}\right)$. Volume and power rating of each tank were optimized for maximum hot water delivery and best energy saving configuration.

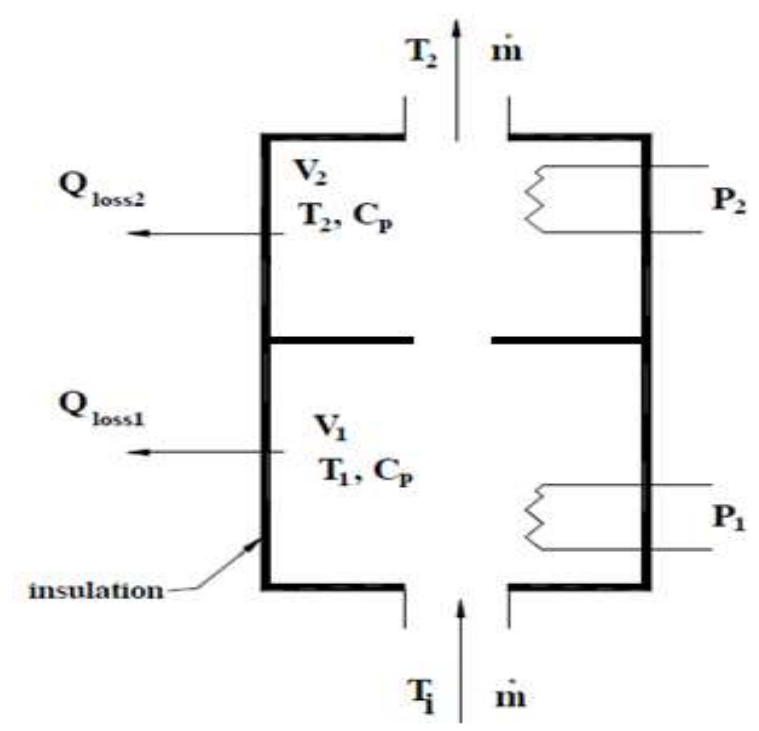

Fig. 3. Schematic diagram of a dual tank EWH [1] 
The transient energy balance for the first tank and second tanks are

$$
\begin{aligned}
& \rho V_{1} C_{P} \frac{d T_{1}}{d t}=P_{1}+\dot{m} C_{P}\left(T_{\mathrm{in}}-T_{1}\right)-A_{1} U\left(T_{1}-T_{\mathrm{a}}\right), \\
& \rho V_{2} C_{P} \frac{d T_{2}}{d t}=P_{2}+\dot{m} C_{P}\left(T_{1}-T_{2}\right)-A_{2} U\left(T_{2}-T_{\mathrm{a}}\right),
\end{aligned}
$$

where $T_{1}$ and $T_{2}$ are the temperatures of hot water in the tank partitions 1 and $2, A_{1}$ and $A_{2}$ are the corresponding surface areas of the partitions, $\dot{m}$ is the hot water flow rate through the heater. It should be noted that the second tank is the tank from which the hot water is supplied. Therefore the temperature of the second tank, $T_{2}$, is of importance.

Dual tank EWHs were simulated with the same data as for the single tank EWHs. Total tank sizes were chosen to be 100, 200, 300, 4001 . Power ratings of 1, 2,3 and $4 \mathrm{~kW}$ were used during optimization. Volume of the upper partition was selected to be $25 \%$ of the total volume and the power rating of the upper heater was $75 \%$ of the total power rating [1]. This power rating ratio was reinvestigated by the authors to see if it really minimized the energy expenditure. It was found to be the optimum ratio as minimum amount of energy was consumed this way throughout the five days. To build on these findings, these two ratios were used in the following comparisons.

\section{Optimization results}

In this section, the results of the comparisons will be given. These comparisons are presented in graphical form to understand the changes with respect to volume and power rating. Hot water increase and energy consumption decrease were plotted for each comparison.

\subsection{Single tank vs dual tank with on-off control}

Results of the simulations of single and dual tank EWHs were evaluated and compared. The first comparisons were made between single tank EWHs and dual tank EWHs with on-off control system. For these dual tank EWHs, both of the heaters are turned on and off at the same time. If the temperature in the second tank falls below $60^{\circ} \mathrm{C}$, both of the heaters turn on. If the temperature rises above $65^{\circ} \mathrm{C}$ both of the heaters turn off. In order to determine whether it would be beneficial to have a dual tank EWH with on-off control, hot water outputs (Fig. 4) and energy consumptions (Fig. 5) of single and dual tank EWHs were compared. The positive values in these graphs indicate the volume and power rating values for which the dual tank EWH with on-off control was more advantageous over the single tank EWH. It can be seen that the dual tank EWH with on-off control was more advantageous for all volume and power rating values. However, there is only one exception to this when the tank size is 1001 and power rating is $1 \mathrm{~kW}$. As for maximum hot water output, single tank model produced 2301 while double tank model with on-off control yielded 2671. 


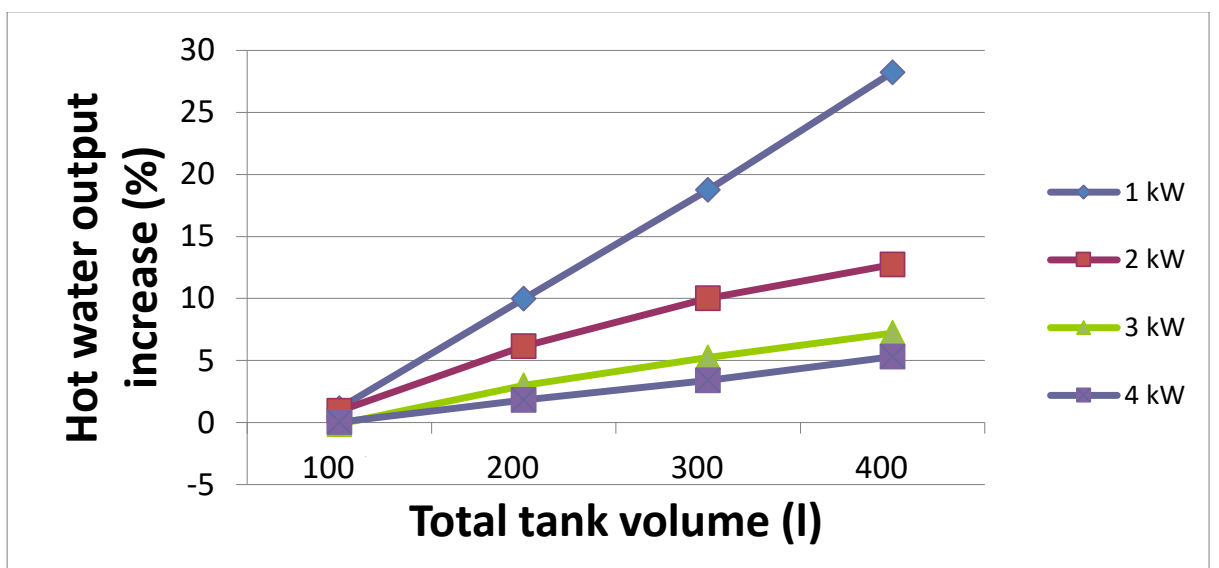

Fig. 4. Hot water output improvements of dual tank EWH with on-off control over single tank EWH

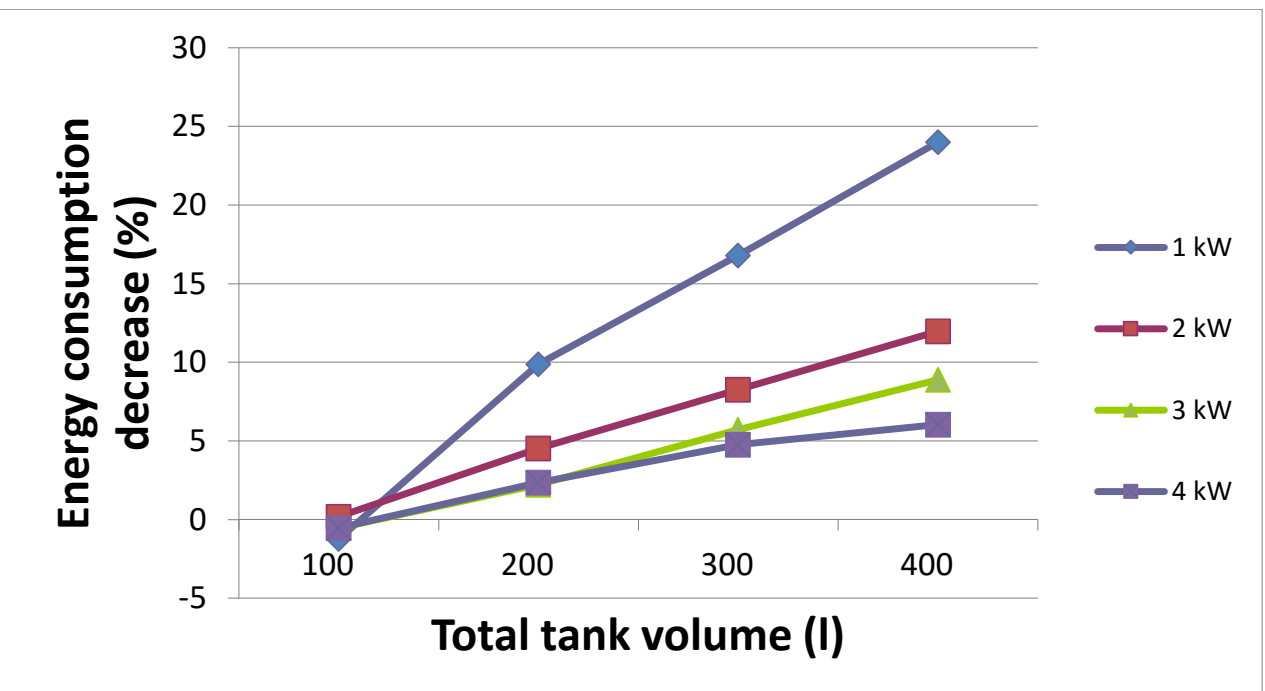

Fig. 5. Energy consumption improvements of dual tank EWH with on-off control over single tank EWH

3.2. Dual tank with on-off control vs. dual tank with first tank prioritized to heat

After that, dual tank EWHs with on-off control were compared with dual tank EWHs with the first tank prioritized to heat. (It should be noted that the first tank has the larger volume with less power rating.) The control mechanism in this type of developed dual tank acts in accordance to the water temperature in the second tank, $T_{2}$. When $T_{2}$ is less than $60{ }^{\circ} \mathrm{C}$, both of the heaters are turned on to heat the water as fast as possible. If $T_{2}$ is still prone to fall below $60^{\circ} \mathrm{C}$ in the second tank due to water flow, both of the heaters stay on. If on the other hand $T_{2}$ has a tendency to be greater than $65^{\circ} \mathrm{C}$, the second tank's heater turns off as the first tank is prioritized to heat. The first tank's heater continues to heat the water until $T_{2}$ becomes $65^{\circ} \mathrm{C}$. If it exceeds $65^{\circ} \mathrm{C}$, the cooling period begins. In all cases, it is important to consider the flow rate 
because incoming water can cause excessive cooling. If $T_{2}$ is likely to fall below $60{ }^{\circ} \mathrm{C}$ because of this phenomenon, then both heaters stay on. However if it is understood that $T_{2}$ will not fall below the acceptable range, then only the first heater stays on. Still, if there is no cooling, both heaters are turned off until $60^{\circ} \mathrm{C}$ are reached. Then, the system goes into heating period again.

The comparisons between this kind of developed EWH with the first tank prioritized to heat and the one with on-off control were done in terms of their hot water output (Fig. 6) and energy consumption rates (Fig. 7). In these graphs positive values indicate where the EWH with the first tank prioritized to heat is more advantageous. It is seen that for all power ratings and volumes the developed model is more advantageous than the one with on-off control in terms of hot water output. In terms of energy consumption however, for larger volumes and smaller power ratings on-off control is more advantageous.

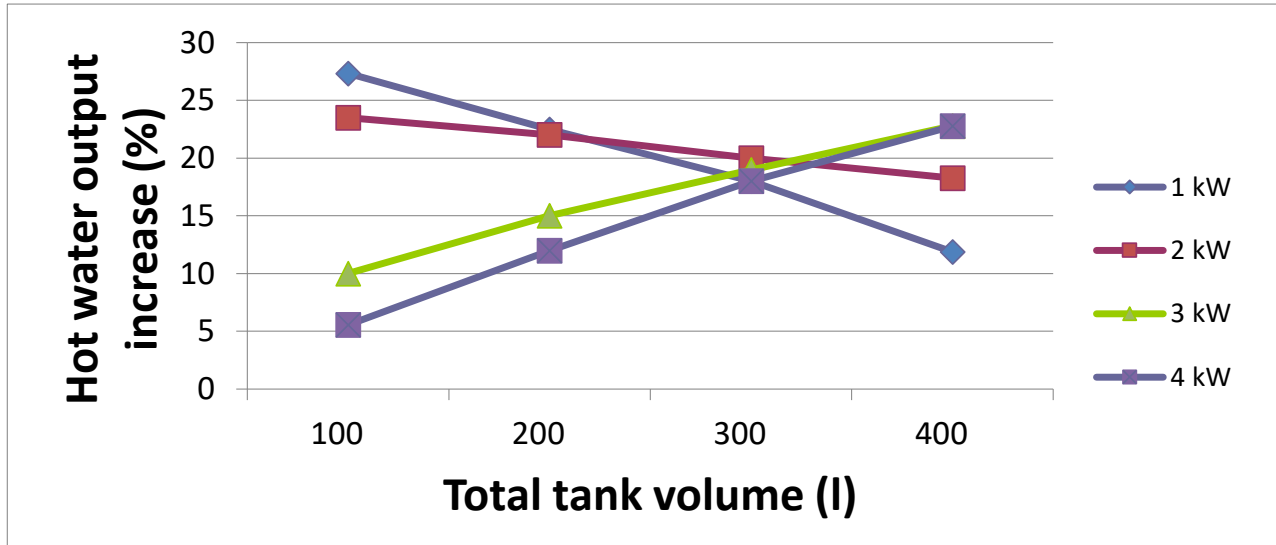

Fig. 6. Hot water output improvements of developed dual tank whose first tank has priority to heat over dual tank EWH with on-off control

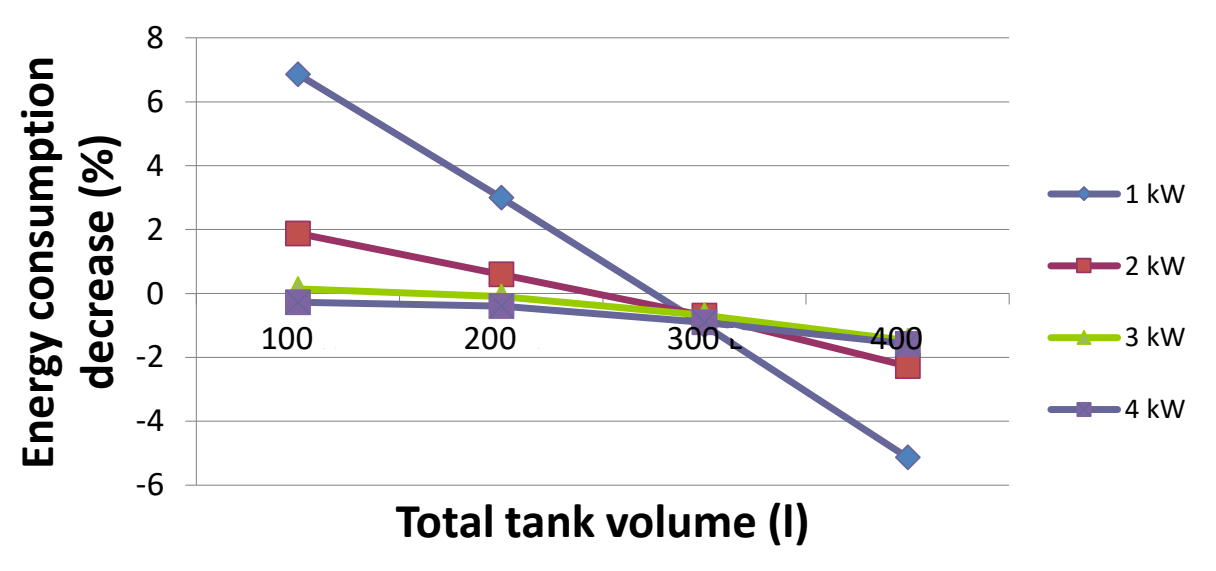

Fig. 7. Energy consumption improvements of developed dual tank whose first tank has priority to heat over dual tank EWH with on-off control 


\subsection{Dual tank with first tank prioritized to heat vs single tank}

Later, the efficiencies of the developed dual tank EWHs with the first tank prioritized and the single tank EWHs were evaluated. The results for this set of comparisons are shown in Figs 8 and 9. Positive values indicate the areas where the developed dual tank model is more advantageous than the single tank model.

It was seen from the simulations that the control mechanism of this type of developed EWH provided a maximum of 3401 of hot water. Also, for all power ratings and volumes the developed dual tank model with the first tank prioritized to heat provided better results than the single tank model did for both criteria.

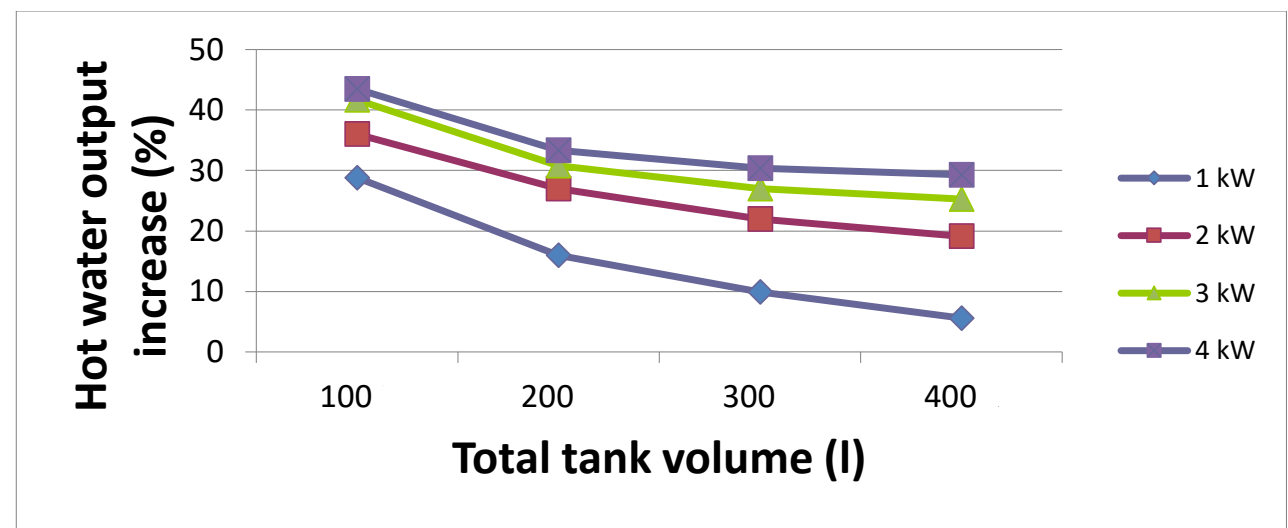

Fig. 8. Hot water output improvements of developed dual tank whose first tank has priority to heat over single tank EWH

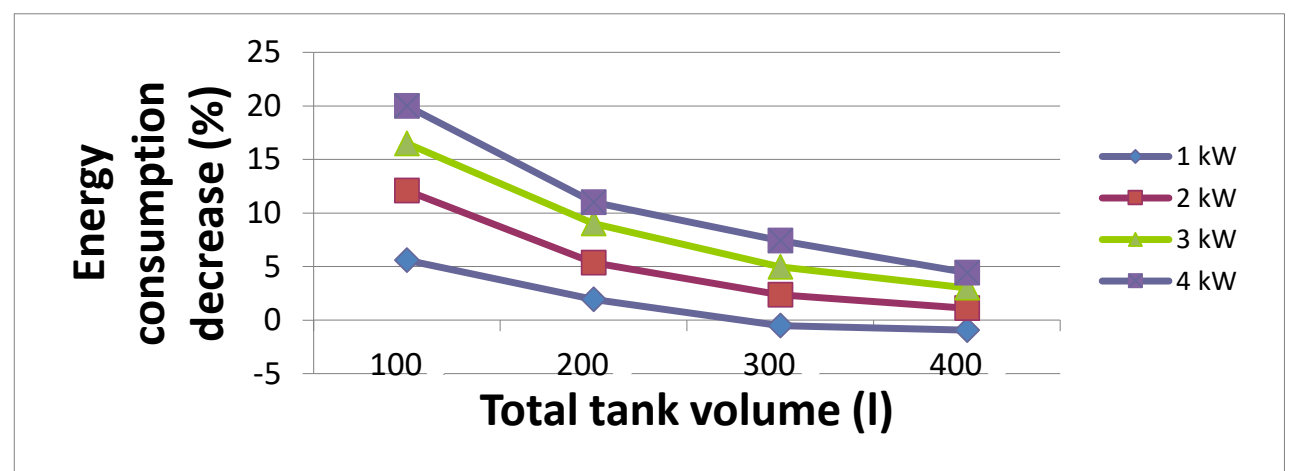

Fig. 9. Energy consumption improvements of developed dual tank whose first tank has priority to heat over single tank EWH

\subsection{Dual tank with second tank prioritized to heat vs single tank}

The second set of developed dual tank EWHs had the second tank (with the smaller volume and more power rating) prioritized to be heated by the control mechanism. This design has a control mechanism that is quite similar to the previous one. In this control mechanism, when $T_{2}$ is less than $60^{\circ} \mathrm{C}$, both of the heaters turn on to heat the water as fast as possible. If $T_{2}$ is prone to fall below $60^{\circ} \mathrm{C}$, both of the heaters stay on. On the other hand, if $T_{2}$ has a tendency to exceed $65^{\circ} \mathrm{C}$, the first tank's heater 
turns off and the second tank is prioritized to heat. The second tank's heater continues to heat the water until $T_{2}$ becomes $65^{\circ} \mathrm{C}$. If it exceeds $65^{\circ} \mathrm{C}$, the cooling period begins. If it is prone to fall below $60^{\circ} \mathrm{C}$, then both heaters stay on. Again if it is determined that $T_{2}$ will not fall below the acceptable range, then the second heater stays on. If still there is no cooling, both heaters are turned off until $60^{\circ} \mathrm{C}$ are reached. Then, the system goes into heating mode again. It is always important to take the flow rate into consideration since too much cooling can occur because of excessive incoming flow.

Single tank EWHs were compared with these developed dual tank EWHs. The results are plotted on Figs 10 and 11. Positive values indicate where the developed dual tank model is superior to single tank model and negative values indicate the opposite. For low power ratings and high volumes, the hot water outputs of these developed EWHs were less than it was for the single tank model. It was seen that this kind of developed dual tank EWH produced an output of 2211 of hot water, which is much less than the quantity produced when the first tank was prioritized to heat. However, the energy consumption for this dual tank EWH is much lower than it is for the single tank EWH for all volumes and power ratings.

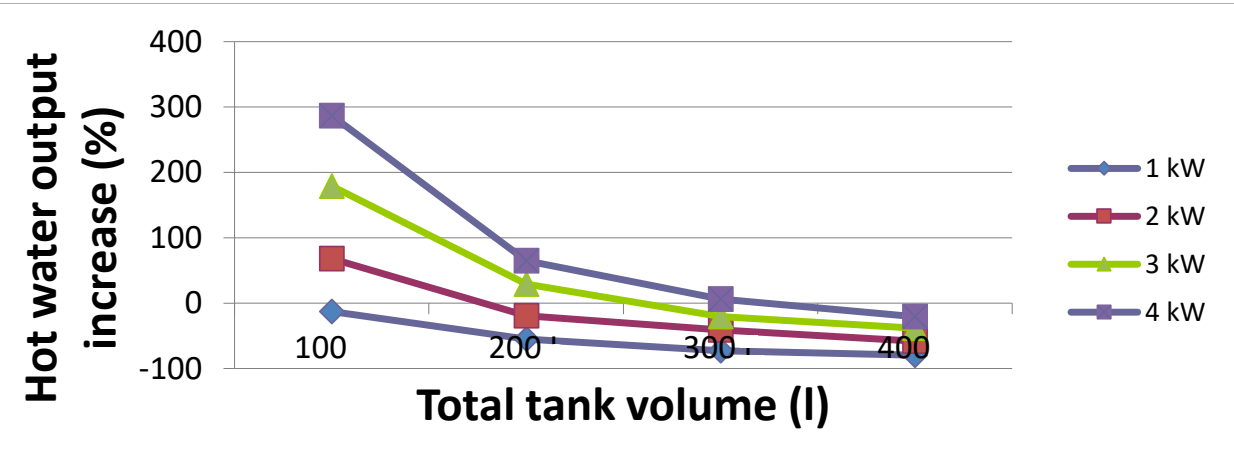

Fig. 10. Hot water output improvements of developed dual tank whose second tank has priority to heat over single tank EWH

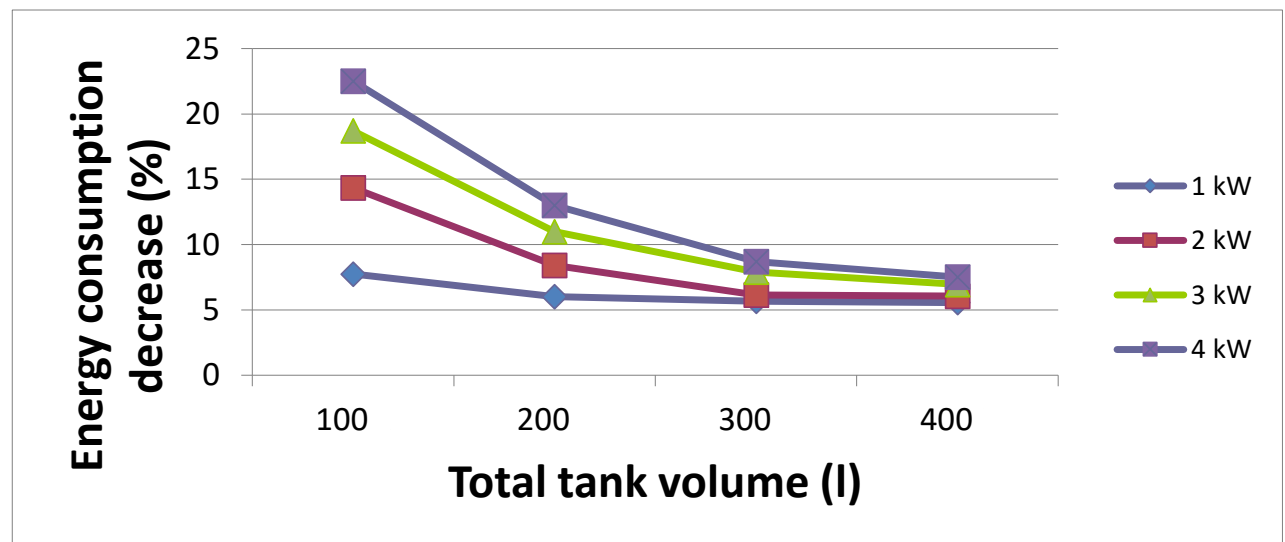

Fig. 11. Energy consumption improvements of developed dual tank whose second tank has priority to heat over single tank EWH 
3.5. Dual tank with first tank prioritized to heat vs. dual tank with second tank prioritized to heat

Finally, the two types of developed dual tank EWHs were compared with each other. The results of these comparisons with respect to on hot water output (Fig. 12) and energy savings (Fig. 13) were plotted. This time, the positive values indicate where the model with the first tank prioritized to heat is more advantageous. It is seen that in all cases for both criteria, prioritizing the first tank to heat is more beneficial.

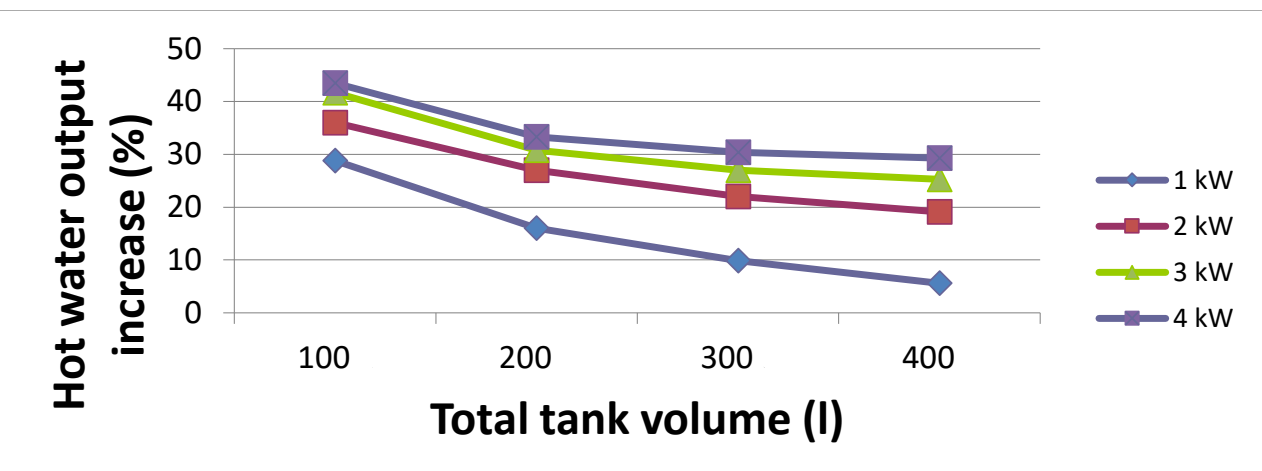

Fig. 12. Hot water output improvements of developed dual tank developed dual tank whose first tank has priority to heat over developed dual tank whose second tank has priority to heat

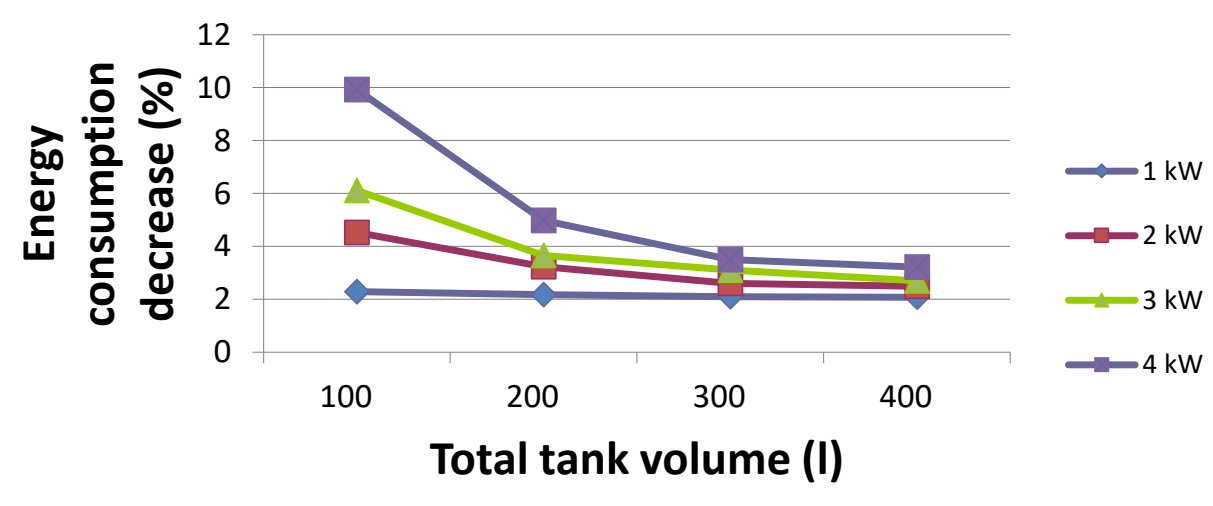

Fig. 13. Energy consumption improvements of developed dual tank whose first tank has priority to heat over developed dual tank whose second tank has priority to heat

\subsection{Energy cost analyses during heating period for both tank types}

According to mentioned control mechanisms, heaters are controlled at time $t$ according to the flow rate at time $t+1$, the possible temperature values at time $t+1$ is checked. If water temperature in the second tank $T$ stays below $65{ }^{\circ} \mathrm{C}$ at time $\mathrm{t}+1$ when both heaters are "on" at time $t$, the heaters stays "on". However, if the temperature has a tendency to become higher than $65^{\circ} \mathrm{C}$ at $t+1$, first, the first heater with smaller power rating becomes "off" and the second heater heats the tank. If the temperature at $t+1$ is more than $65^{\circ} \mathrm{C}$, the second heater with higher power rating 
becomes "off" and the first heater heats the tank. This procedure takes place until the temperature of the second tank reaches $65^{\circ} \mathrm{C}$.

When the water temperature in the second tank exceeds $65^{\circ} \mathrm{C}$, the heaters again enter into the cooling period. In order to optimize the cooling and the water flow, we again check the temperature change at $t+1$. If the temperature has a tendency to decrease although both heaters are "on" at $t$, the heaters stay "on". However, if the water temperature inside the tank does not decrease, first, the first heater with smaller power rating becomes "off" and the second heater stays "on". If the temperature does not decrease, the second heater with higher power rating becomes "off" and the first heater stays "on" this time. If cooling takes effect, the heaters stay as it is stated. If not, both heaters become "off" and the tank is left to cool down. As a result, although the water temperature is allowed to decrease, it is done slowly. However this resulted in high increase in energy consumption and did not have any considerable effect on increase of flow rate. At this point stratification is important.

In the following tables cost analyses for single and double tanks will be given. Since there will be some time needed for the water to warm, some water and energy will be wasted while waiting for the outlet temperature to reach $62.5^{\circ} \mathrm{C}$. This is wasted energy. To minimize this energy loss, transient analysis on FLUENT was performed to see how long it took for the outlet water temperature to reach $62.5^{\circ} \mathrm{C}$. On the last columns of Tables 1 and 2 this wasted energy's cost is given in currency units (cu).

Table 1. Cost analysis for single tank with respect to power rating

\begin{tabular}{|c|c|c|c|}
\hline Power rating $(W)$ & Time waited & Energy consumption $(J)$ & Cost of energy $\left(10^{-4} \mathrm{cu}\right)$ \\
\hline 45 & 9.50 & 1704.74 & 4.74 \\
\hline 50 & 9.15 & 1688.27 & 4.69 \\
\hline 65 & 8.19 & 1632.84 & 4.54 \\
\hline 75 & 7.60 & 1591.79 & 4.42 \\
\hline 80 & 7.32 & 1570.30 & 4.36 \\
\hline 100 & 6.31 & 1479.45 & 4.11 \\
\hline 125 & 5.24 & 1359.40 & 3.78 \\
\hline
\end{tabular}

* $\mathrm{kWh} \times$ Currency unit

Table 2. Cost analysis for double tank with respect to power rating

\begin{tabular}{|c|c|c|c|}
\hline Power rating $(W)$ & Time waited & Energy consumption $(J)$ & Cost of energy $\left(10^{-4} \mathrm{cu}\right)$ \\
\hline 30 & 6.241469162 & 937.42 & 2.60 \\
\hline 45 & 5.509178928 & 910.07 & 2.53 \\
\hline 50 & 5.284698647 & 899.41 & 2.50 \\
\hline 65 & 4.664663026 & 863.86 & 2.40 \\
\hline 75 & 4.292269428 & 837.82 & 2.33 \\
\hline 80 & 4.117374065 & 824.27 & 2.29 \\
\hline
\end{tabular}

$* \mathrm{kWh} \times$ Currency unit

As can be seen from both tables the cost of energy decreases as power rating increases. This is due to the fact that water's faster heating compensates for more than the increase in power. Therefore higher power ratings are more economical when they are analyzed for the lost energy during the heating period. 


\section{Discussion}

In this study, optimum design and selection of storage type EWHs were investigated and compared by simulating five days of typical household operation. Single and double tank EWHs of various tank sizes and power ratings were examined using an average hourly hot water usage profile. The result of a previous study [1], which stated that dual tank EWHs, where the size of second tank was $25 \%$ of the total tank volume and the power rating was $75 \%$ of the total power rating, provided more hot water and used less energy per 1 of hot water. This result was validated in this study once again. Therefore, to obtain the optimum design, these ratios were used in dual tank EWHs modelled for this study.

Single tank heaters performed worse than dual tank EWHs with on-off control. Especially for lower power rates and a tank size of 400 1, the dual tank EWHs with on-off control produced more hot water. Energy consumption was also very low in dual tank EWHs with on-off control, except for a tank size of 100 l. Dual tank EWH with on-off control was also compared with developed dual tank EWH whose first tank was prioritized to heat. Hot water output performance of developed dual tank was very good for all power inputs and tank sizes but its energy consumption for higher tank sizes and lower power inputs was greater and disadvantageous. Other comparisons were made between dual tank whose first tank had priority to heat and single tank EWH as well as between dual tank whose second tank has priority to heat and single tank EWH. Even though dual tank whose first tank has priority to heat produced more hot water than single tank model, the performance of dual tank whose second tank has priority to heat was worse than that of the single tank EWH. However, energy consumption rates per liter of developed dual tanks were better than single tank in general.

It was concluded that, in general, single tank EWHs produced less hot water than dual tank EWHs except dual tank EWH whose second tank had priority to heat. Dual tank EWH whose second tank had priority to heat performed the worst. The performance of this dual tank EWH decreased during the five days of operation because of an excessive decrease in water temperature of the first tank. The reason is that the second tank has a lower volume with a more powerful heater. Thus, it cannot compensate for the sudden increases in water flow. However, when dual tank EWHs were compared with single tank EWHs, it can be said that on a daily basis, dual tank models provided more hot water with less energy consumption for five days.

Also, from the simulation data, it was seen that the amount of hot water provided by single tank EWHs did not vary with tank size but it varied with power rating. This means that even $1 \mathrm{~kW}$ of power is enough to keep the output water temperature in the acceptable range for a tank volume of 4001 . However, energy consumption increased with increasing tank volume, which means that the heater had to be turned on for a longer period.

In addition to on off and preview controls, the thesis includes other type of control mechanisms like as P, PI and PID control mechanisms. In our P, PI and PID control mechanisms, the reference temperature was $62{ }^{\circ} \mathrm{C}$ and the output water temperature oscillated around this value. It was performed that the simulations with 
different coefficients so it is possible to get different results with different coefficients.

The integral term is a term that eliminates the steady state error of the system. It causes overshoots in the system and sometimes it leads the system to be unstable. Basically, in our control system, we did not get the steady state error because the temperature range was $60-65^{\circ} \mathrm{C}$ and the deviations from $62^{\circ} \mathrm{C}$ were acceptable.

It was found that there was not any significant difference between P and PD control. However, if the control coefficients changed, our simulation results would be changed. It was found that the energy saving was not an important characteristic for PID control mechanism.

Due to user's satisfaction, time period for the water to warm, should be short. According to comparisons some time needed for the water to warm, some water and energy will be wasted while waiting for the outlet temperature to reach steady state conditions. This is wasted energy. To minimize this energy loss, power ratings have to be increased.

In the future, more work may be done on the control mechanism of the dual tank EWHs. PID controller gains with the most efficient output can be determined and applied. Then, this control mechanism can be tried against the ones presented in this paper.

A certain hot water use profile by Becker, obtained from the hot water use patterns of the USA households, is used in this thesis [4]. There are different profiles in open literature, obtained from data on different countries. However, these profiles could be in need of change. In order to continue on work in this area, hot water use profile of household in big cities of Countries should be obtained.

A better model can be designed for stratification of the electrical water heater. Some experimental, analytical and computer studies are available in the open literature, but none takes into account electrical water heating element and its dynamics. Most models use tank as hot water usage not for hot water heating. Thermal stratification is a significant performance parameter for thermal energy storage tanks. The thermal stratification of vertical mantled hot water tank would be investigated by placing different obstacle inside the tank [7].

Industrial applications of the obtained results can be implemented and compared with the theoretical works with cooperation of electrical hot water heater manufacturers or Model Predictive [8].

Other types of energy resources can be used to produce domestic heating water and different control mechanisms can be applied. After that it can be compared performance of water heaters working with different energy types.

\section{References}

1. K a r, A. K., U. K a r. Optimum Design and Selection of Residential Storage Type Electric Water Heaters for Energy Conservation, Energy Convers. - Mgmt, Vol. 66, 1996, pp. 12-24.

2. F 1 o s s 1, A., S. H o f m a n n. - Energy and Buildings, Vol. 100, 2015, pp. 10-15.

3. Kre u z inger, T., M. B i t z e r, W. Marquard t. State Estimation of a Stratified Storage Tank. - Control Engineering Practice, Vol. 16, 2008, pp. 308-320.

4. B e c k e r, B. R., K. E. S t o g s di 11 . A Domestic Hot Water Use Database. - ASHRAE Journal, Vol. 32, 1990, pp. 21-25. 
5. K a r, A. K., K. M. A 1-D o s s a r y. Thermal Performances of Water Heaters in Series. - Appl. Energy, Vol. 52, 1995, pp. 47-53.

6. C e n g e 1, Y. A., M. A. B o le s. Thermodynamics on Engineering Approach. Eight Edition in SI Unit. New York, McGraw-Hill, 2015, pp. 91-175.

7. E r d e m i r, D., N. A l t u n to p. Improved Thermal Stratification with Obstacles Placed Inside the Vertical Mantled Hot Water Tanks. - Applied Thermal Engineering, Vol. 100, 2016, pp. 20-29.

8. Ji a $\mathrm{f}$ e n g, Q., W. Ch a n g f e n g. Safety Risk Management in Large Scale Engineering Based on Model Predictive Control. - Cybernetics and Information Technologies, Vol. 14, Special Issue, 2014, pp. 17-27. 